\author{
Renewable and Nonrenewable Energy \\ Vol: 1(1), 2022 \\ REST Publisher; ISBN: 10978-81-948459-2-8
}

Website: http://restpublisher.com/book-series/renewable-and-nonrenewable-energy/

\title{
Design and Performance Analysis of Biomass Cook stove with Thermoelectric Generator
}

\author{
*R.Vijay, D.Balaji, K.Kumaresan, S.Mohamed javith , S. Mohamed anas \\ Department of Mechanical Engineering, Arasu Engineering College, Kumbakonam, Tamil Nadu, India. \\ *Corresponding author Email: vijayfalcon92@gmail.com
}

\begin{abstract}
The aim of the paper is to design and evaluate the performance of an energy efficient biomass combustion store fitted with thermoelectric generator to produce both thermal energy and electrical energy from a single fuel source. The combustion chamber in the stove is designed in a way to utilize the primary and secondary air to provide complete combustion by not using any external source such as blower. Due to complete combustion process the stove never produces smoke which causes asthma and other respiratory diseases for women and children. The cook stove is fitted with a light and electric charger arrangement. This stove can be used in rural and hilly regions for producing thermal, light and electrical energy. The new design in the cook stove have been made for the better usage of sustainable energy and reducing worst impact of climate change on environment. Biomass cook stove is a combustion device which liberates a lot of lot of thermal process during cooking process. In the newly developed TEG biomass cook stove the liberated waste heat energy is utilized for the generation of electricity with the help of thermoelectric generator and the electrical energy is stored in a li-ion battery which is used for lighting a led light and charging a mobile phone. Water boiling test which ic used to measure the performance of cook stove was carried out in this stove and the stove is found to be efficient in the conversion of biomass fuel into thermal and electrical energy. This cook stove has been deployed in the rural areas to check its usability, viability, electrical and thermal performance under the umbrella of clean combustion.
\end{abstract}

Keywords: TEG, Li-Ion Battery, Led Light, Primary and Secondary Air.

\section{Introduction}

In this present work the biomass combustion stove is designed in such a way with an efficient combustion for providing complete combustion process and a thermoelectric energy. The electrical energy is stored in Lithium Ion Batteries for further electrical utilization such as charging a mobile phone or lighting a LED Light. B.M. Jenkins, L.L. Baxter T.R. Miles Jr., T.R. Miles, Fuel Proc. Tech. (1998). Low cost and widespread distribution are one of the most important advantages attributed to the utilization of renewable energy of solid biomass. Solid biomass waste can be used as a source of renewable energy in the household and small industry sector for cooking in the rural area of West Bandung District, West Java, Indonesia. This solid biomass is crop residues from agricultural plantations such as corncob, coconut shell, and wood chips. S. P. Snood, Y. P. Khandetod, A. G. Mohod, R. M. Dharaskar, K. G. Dhande, Adv. Agr. Research Tech. J. (2000) As a comparison of this work, Soot, et .reported the current developed cook stove in natural convection using mango sticks biomass as fuel. The maximum flame temperature and average thermal efficiency of $17.44 \%$ and $894{ }^{\circ} \mathrm{C}$, respectively were attained in this studied . Suhartono, B. D. Prasetyo, I. N. Azizah, J. Eng. Appl. Sci.(2001) As an example, the corncob waste from agricultural plantations in this area was estimated at 11,960 tons/year with potential energy approximately 46,903,064 $\mathrm{MJ} / \mathrm{year}$ The thermal power input was calculated based on specific fuel consumption of the fuel amount needed to boil the amount of water. M. Sharma, H.S. Mukunda, G. Sridhar, Energy Conv. Management (2004) In this parametric study, wood chip showed better performance in term of combustion time, thermal power input and thermal efficiency. In this work, coconut shell exhibits lower combustion time than the wood chip. This behavior is caused by higher ash content and therefore the thermal power of coconut shell is lower than wood chip due to the low volatile release rate. H.S. Mukunda, P.J. Paul, N.K.S. Rajan, S. Dasappa, M. Yagnaraman, D.R. Kumar, M. Deogaonkar, Current Sci.(2005) The adequate combustion air, flame temperature, and pollutant emissions can be taken as the indication of combustion quality. The sufficient air is required for the combustion reaction to produce a flammable gas to obtain maximum flame temperature and low pollutant emissions. The air draft was supplied through a large number of holes of small diameter. The superficial velocity of the biomass stove is one of the most important measures of its performance. B.M. Jenkins, L.L. Baxter T.R. Miles Jr., T.R. Miles, Fuel Proc. Tech.(2006) The slight change in color of the flame may be due to the moisture content and hydrocarbon in fuel being combusted in the combustion zone. The equivalent ratio determines whether the stove is operating in a complete combustion, while the flame temperature can be taken as the indication of the calorific value of the fuel and quantity of combustible gas produced. This stove will be equipped with a flue gas cleaning system using absorbent graphite waste modified with $\mathrm{Fe} 3 \mathrm{O} 4$ adsorbent magnetite nanoparticles to reduce more levels of $\mathrm{CO}$ and $\mathrm{CO} 2$ emissions'. Lalovic, $\mathrm{Z}$. Radovic, N. Jaukovic, Materiali in Technologije (2012) the flame temperature can be considered to be a function of fuel quality and to be dependent on the parameters of the conditions of the fuel-combustion process. D. R. Nhuchhen, M. T. Afzal, Bioengineering. (2013) the pollutant emissions generated by combustion critically related to the properties of 
biomass as fuel.The biomass size also has an effect on combustion, thick biomass will combustion slowly causing the residence time in the combustion chamber becomes longer. S.C. Bhattacharya, D.O. Albina, A.M. Khaing, Biomass, and Bioenergy.(2015) The flame temperature shown by the corncobs was also constant but lower in value than that of wood chip. It can be concluded that constant temperature can be obtained in this designed stove by utilized this biomass. S. Narnaware, D. Pareek, Int. Energy J (2018) the smaller equivalent ratios when operating at lower thermal power input (small fuel loaded) and slightly higher as the thermal power input increase. It can be explained that when a small amount of fuel allows the air faster supply due draft flow because of the sufficient free space on the stove. However, the higher equivalent ratio, $\Phi>1$ (fuel rich mixture/air deficiency) lead to increase quenching and cooler combustion temperatures might promote incomplete combustion and reduced thermal efficiency Standards \& Testing. Global Alliance for Clean Cookstoves. (2019) An Alliance-coordinated multinational multi-disciplinary approach, including the development of standards and testing, is designed to improve global health and the environment through clean cooking solutions. International Workshop Agreement 11: 2019 Guidelines for Evaluating Cookstove Performance. Final Draft.(2019) the cookstove system was tested using the Water Boiling Test (WBT) Version 4.2.3 (8) and following the ISO International Workshop Agreement Guidelines for Evaluating Cookstove Performance.

\section{Materials and Method}

Materials: The Biomass combustion stove is fabricated with mild steel solve to its high strength and temperature resistance properties. The combustion chamber is coated with Plaster of Paris insulation because during the combustion process heat is produced at high temperature and it get lost due to conduction, convection and radition process. The provisions for providing primary and secondary air for the complete combustion of biomass is made around the combustion chamber. Lithium-ion batteries are used for electrical energy storage purpose due to its high energy density characteristics thermoelectric generator which is used for the conversion of heat into electricity with the help of seebeck effect is made of Silicon-germanium alloy Aluminium tube connected to the Thermoelectric generator for the conducting the heat from combustion chamber to the TEG modules. Aluminium is used because of its high thermal conductivity. These are the materials which are fabricated and assembled to form the TEG cookstove.

Methods: The mild steel is welded to produce the rectangular support for the combustion cookstove and cylindrical section of mild steel is welded and connected to the rectangular support. The inner layer of the combustion chamber is coated with Plaster of Paris insulation for reducing the heat loss. Thermoelectric generator with aluminium is connected together with the help of thermal glurry paste the electric energy which is generated in the TEG directly through a resistor a LED light is connected to the battery for providing lightening during the time of power cut. The aluminium which is fitted with TEG and lithium ion battery is kept in a rectangular box and this whole set up can be assembled near a fine source or any other combustion system.

\section{Formulae}

Mass Burning rate of wood (Biomass) : $M=14 * 9.81 * \pi / 4 * d$

Amount of energy liberation during combustion released: $E=c v / 1000$

Thermal efficiency: $(\eta)$ Thermal $=\frac{\text { workdone }}{\text { Heat supplied }}$

Heat supplied: Heat Supplied $=\mathrm{Mf} * \mathrm{Cv}$

Work done: Work done $=\mathrm{p}={ }_{\mathrm{mf} * \mathrm{CV}}$

Burning capacity rate $:=2(\mathrm{M} 1-\mathrm{M} 2) * \mathrm{CV}$

Mass burning rate of wood pellets with time taken: $\mathrm{p}=>\frac{M g * C v}{t}$

Efficiency of TEG: $\eta=$ pout/q in

Area of the grate: $\mathrm{Ag}=180 / 4 \mathrm{xd}^{2}$

\section{Nomenclature}

$\mathbf{E}=$ amount of energy liberated during combustion $(\mathrm{kj} / \mathrm{g} / \mathrm{s})$

$\eta=$ thermal efficiency

$\mathrm{Ag}=$ area of the grate $\left(\mathrm{cm}^{2)}\right.$

$\mathrm{CV}=$ calorific value $\left(\mathrm{kj} / \mathrm{kg}^{\mathrm{Ok}}\right)$

$\mathrm{Mf}=$ mass of the fuel $(\mathrm{kg} / \mathrm{s})$

$\mathrm{D}=$ diameter of the stove $(\mathrm{cm})$

$\mathrm{Q}=$ heat supplied $(\mathrm{kW})$

\section{Water boiling test}

The temperature at which a pure organic substance changes from the liquid phase to the gas phase is known as the boiling point. A liquid's boiling point can be determined using the capillary method, where an inverted capillary is placed in the liquid of interest and the liquid is heated. As the temperature increases, the air in the capillary escapes and is replaced by the vapor of the liquid. The vapor pressure in the capillary increases with temperature. Once it exceeds the atmospheric pressure, the vapor escapes the capillary in a stream of bubbles. When the heat is removed, the liquid cools, and the vapor pressure in the capillary decreases. When the vapor pressure reaches the atmospheric pressure, the liquid begins to fill the capillary. The temperature at which this occurs is the boiling point. Put on a lab coat, splash-proof safety glasses, and nitrile gloves. This 
experiment must be conducted in a hood. Attach a small test tube to the thermometer using a rubber band, and secure the thermometer in the clamp. Obtain acetone and bring it back to your hood. Using your glass pipette and a bulb, measure $1 \mathrm{~mL}$ of acetone and transfer it into the small test tube. Align the thermometer end so that it is level with the acetone in the test tube, keeping them close to each other. Invert a capillary tube and place it in the test tube so that the open end is facing downwards. Use a $250-\mathrm{mL}$ beaker to create a water bath. Add approximately $180 \mathrm{~mL}$ of water to the beaker, and place it on the hotplate. Lower the thermometer and test tube into the water bath. Turn on the hotplate to the lowest setting, about $30^{\circ} \mathrm{C}$. Slowly increase the temperature on the hotplate by $10-20^{\circ} \mathrm{C}$ every $10 \mathrm{~min}$, and closely observe the liquid in the test tube. When you start to see occasional bubbles in the liquid, increase the heat setting by only $5^{\circ} \mathrm{C}$ every $10 \mathrm{~min}$. closely observe the capillary tube inside the test tube. Report the temperature at which a rapid and continuous stream of bubbles comes out of the capillary. Turn off the heat and allow the water bath to cool. Keep observing the capillary as the production of bubbles decreases until no bubbles emerge from the capillary. The liquid will start to rise in the capillary. Record the temperature at which this occurs. Label a clean $25-\mathrm{mL}$ beaker as 'organic waste'. Once the water bath has cooled to about $35^{\circ} \mathrm{C}$, remove the thermometer and test tube from the bath. Detach the test tube from the thermometer and pour the acetone into the waste beaker. Use a clean test tube and capillary and repeat the experiment using $1 \mathrm{~mL}$ of ethanol. After you have measured the boiling point of ethanol, allow the water bath to cool. Once it
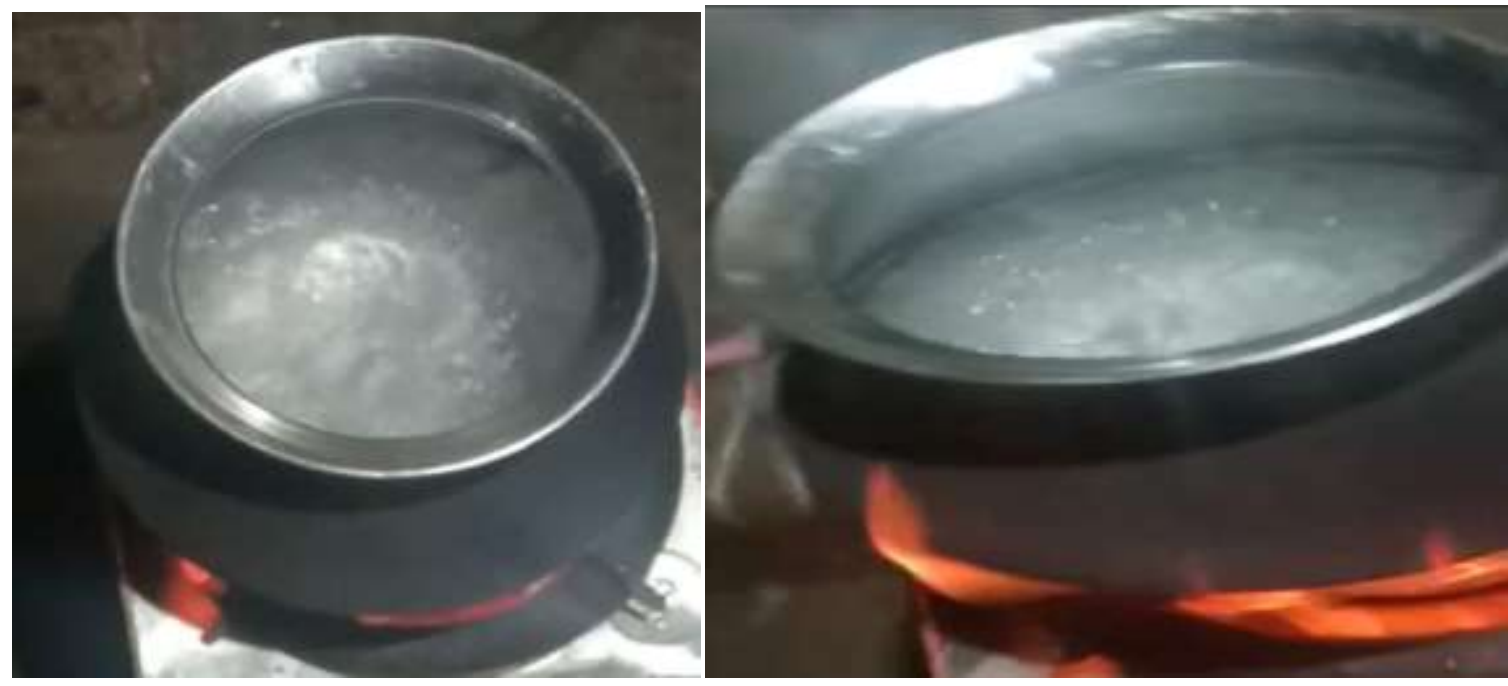

has cooled sufficiently, remove the test tube and thermometer from the water bath, detach the test tube from the thermometer, and pour the ethanol into the organic waste beaker. Dispose of the water from the water bath down the sink and place the capillaries and test tubes in the glass disposal. Dispose of the organic waste in the container provided by your instructor. Wash all of your glassware with detergent and water

\begin{tabular}{|l|l|}
\hline Time(sec) & Boiling point temperature(Celsius) \\
\hline 60 & 20 \\
\hline 120 & 50 \\
\hline 180 & 87 \\
\hline 240 & 93 \\
\hline 300 & 100 \\
\hline 360 & 124 \\
\hline 420 & 152 \\
\hline 480 & 170 \\
\hline
\end{tabular}




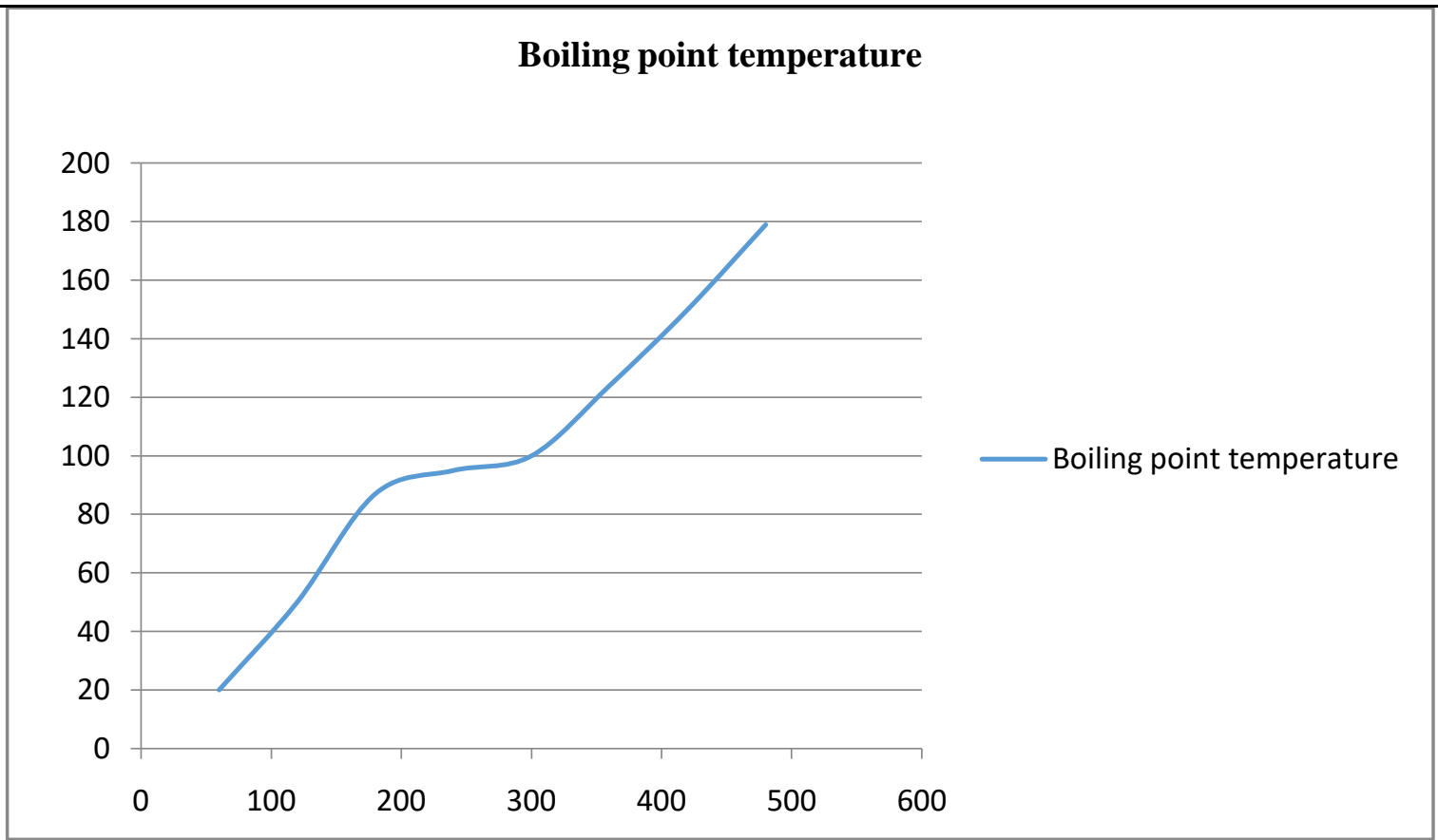

\section{Experimental setup}
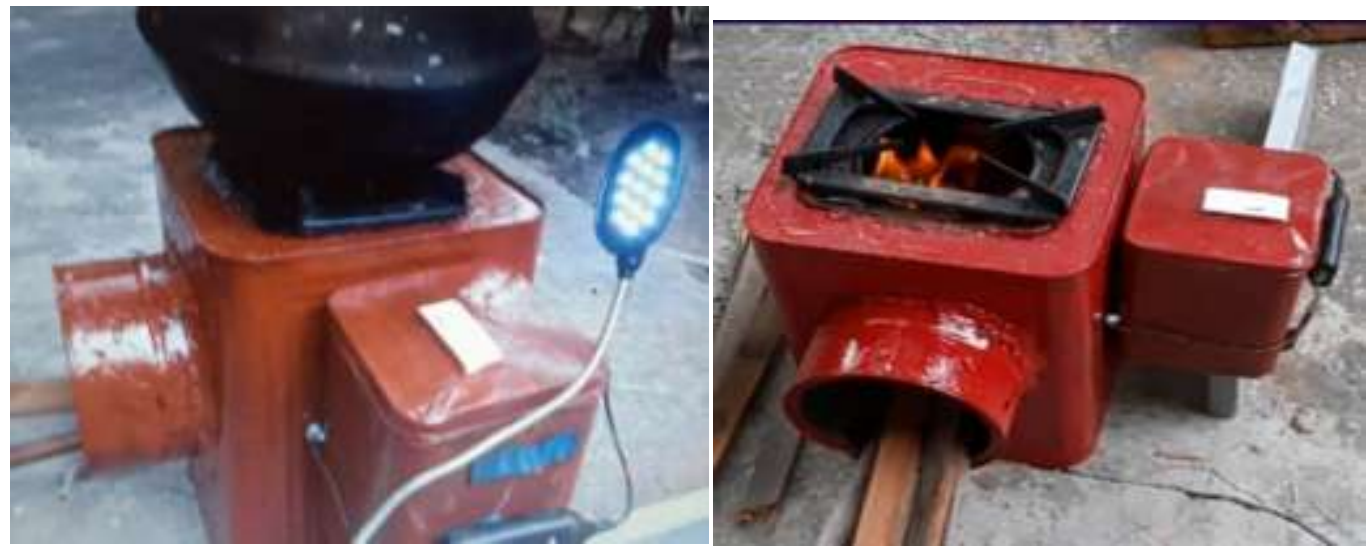

In this biomass cookstove the TEG device can be fitted either both sides as it is we may require. First we are putting biomass wood pellets into the inlet of the biomass stove .then start burning pellets after it will reaching certain temperature then the TEG device can generate electricity by utilizing thermal energy from the stove. This electrical energy stored in li-ion battery. Then it can be further using to charging a mobile phone, lighting and military people they can use for generating electricity when going to camping wherever. It can be more useful for hilly region peoples and rural peoples. It can produce the electrical energy nearly about $4.5 \mathrm{~W}$.In this stove we are using $5 \mathrm{~W}$ TEG then it can produce near value. And then it can be stored the electrical energy up to $4 \mathrm{H}$ duration since, one time we can charged for one hour.

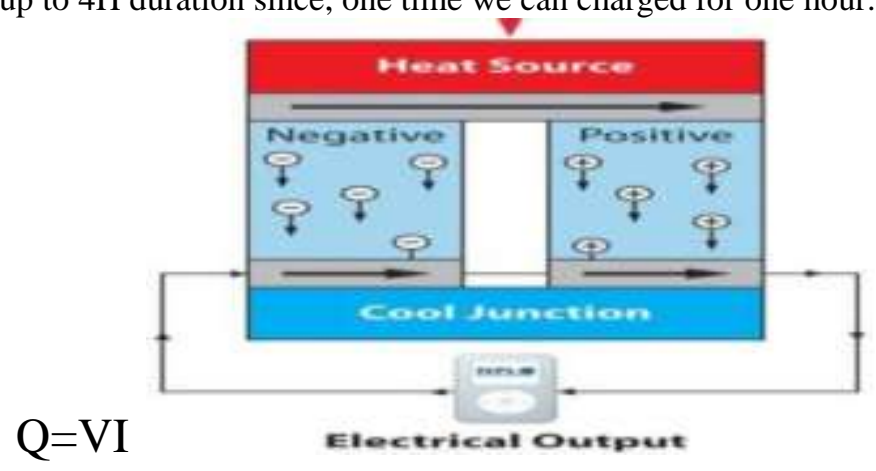

Where,

Principle of thermoelectric generator

$\mathrm{V}$-voltage in volts

I-current in amps 


\section{Result and discussion}

Finally in this biomass cook stove we obtained a good thermal efficiency for combustion and electrical output. The newly designed biomass cook stove produced an electrical output of nearly $4.5 \mathrm{~W}$. In our observation it is found that during one hour burning of biomass which was carried out in the cook stove and it produced electrical energy which can be stored in a battery that can withstand up to 4 hours and it can be used to charge two phones and one light continuously for 4 hours. Combustion efficiency is also increased to a greater extent and less smoke will be produced during cooking. The cook stove reached the boiling point of water in

\section{Conclusion}

The design and performance analysis of biomass cook stove with thermoelectric generator was successfully done and water boiling test was carried out. This type of biomass cook stoves are more useful and helpful rural, hilly regions peoples and found numerous military applications as an auxiliary power source. The newly developed biomass cook stoves will definitely rectify problems faced by women and children during cooking.

\section{References}

[1]. Bhuiyan AA, Karim MR, Naser J (2018) Effect of recycled flue gas ratios for pellet type biomass combustion in a packed bed furnace. Int $\mathrm{J}$ Heat Mass Transfer.

[2]. Gogoi B, Baruah DC (2016) Steady state heat transfer modeling of solid Fuel biomass stove energy.

[3]. Bryden KM, Maccarty NA (2015) Modelling of household biomass cook Stoves: a review. Energy Sustain Dev.

[4]. Fichet V, Plion P, Tabet F (2016) a comprehensive CFD based model for Domestic biomass heating systems. J Energy Inst.

[5]. Still DK, Bentson S, Murrey N, Andres J, Yue Z, Macarty NA (2018) Laboratory experiments regarding the use of filtration and retained heat to Reduce particulate matter emissions from biomass cooking. Energy Sustain Dev.

[6]. Ibarra L, Aragón G, Gomez I, Múgica I, González J, Maroto JR, Rojas E, Sanz D, Ramos R, Escalada R, Borjabad E, Gutierrez-Canas C (2018) Blend design tools for medium combustion plants (MCP) firing biomass Wastes waste Manage.

[7]. Quist CM, Jones RB, Jones MR, Lewis RS (2016) Uncertainty analysis And design guidelines of biomass cookstove thermal efficiency studies. Energy Sustain Dev.

[8]. Grimsby LK, Rajabu HM, Treiber MU (2016) Multiple biomass fuels and Improved cook stoves from Tanzania assessed with the water boiling test. Sustain Energy Technol Assess.

[9]. Chen Y, Shen G, Su S, Du W, Huangfu Y, Liu G, Wang X, Xing B, Smith KR, Tao S (2016) Efficiencies and pollutant emissions from forced-draft biomass-pellet semi-gasifier stoves: comparison of international and Chinese water boiling test protocols. Energy Sustain Dev .

[10]. Kwofie EM, Ngadi M, Sotocinal S (2017) Energy efficiency and emission Assessment of a continuous rice husk stove for rice parboiling. Energy.

[11]. Datta A, Malik JK, Pal RC, Singh VK, Suresh R (2016) Evaluation of the Performance of improved biomass cooking stoves with different solid Biomass fuel types. Biomass Bioenergy.

[12]. Shiehnejadhesar A, Mehrabian R, Hochenauer C, Scharler R (2017) The virtual biomass grate furnace-an overall CFD model for biomass combustion plant. In: INFUB $-11^{\text {th }}$ European conference on industrial furnaces and boilers, Austria.

[13]. Lung MA, Espira A (2019) A large-scale, village-level test of wood Consumption patterns in a modified traditional cook stove in Kenya. Energy Sustain Dev.

[14]. Lombardi F, Riva F, Sacchi M, Colombo E (2019) Enabling combined access to electricity and clean cooking with PV micro grids: new Evidences from a high-resolution model of cooking loads. Energy Sustain Dev

[15]. Paulsen AD, Kunsa TA, Carpenter AI, Amundsen TJ, Schwartz NR, Harrington J, Reed J, Alcorn B, Gattoni J, Yelvington PE (2019) Gaseous and particulate emissions from a chimneyless biomass cook Stove equipped with a potassium catalyst. Appl Energy. 